\title{
Species Occurrence Data for the Nation
}

\section{USGS Biodiversity Information Serving Our Nation (BISON)-A Unique, Web-Based \\ Federal Mapping Resource for Species Occurrence Data in the United States and its Territories}

\begin{abstract}
BISON's size is unprecedented, including records for most living species found in the United States (ITIS, 2019) and encompassing the efforts of more than a million professional and citizen scientists. Most of BISON's species occurrence records are specific locations, not just county or State records (BISON, 2019).
\end{abstract}

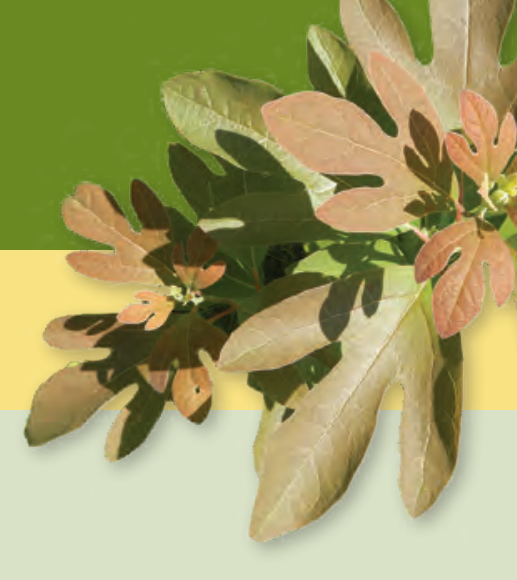

Sassafras (Sassafras albidum) is a native tree whose important medicinal properties have caused it to be extirpated from Wisconsin, which is the edge of its natural range (USGS, 2019).

\section{Web Interface}

\section{Users may query BISON}

(https://bison.usgs.gov) by scientific or common name, and then refine their search results by choosing one or more criteria, including basis of record (such as observation or specimen), provider or resource name, location, higher taxa, year range, marine exclusive economic zone (EEZ), and centroid inclusion/exclusion.

BISON also provides a refined search option for querying the database by selecting a county or State, or by drawing an exact boundary around an area of interest on the map such as protected areas, villages, or even much smaller areas. For instance, BISON maps more than 666,000 occurrences in New York City's Central Park alone, with detailed information available for each species record.

Species occurrence data are displayed in BISON on an interactive map (with heat map or points layer options), or in checklist format. Mapped search results may be displayed on any of 50 available map layers. Users can download their search results in zipped text (.csv), Google Earth KML, or shapefile formats.

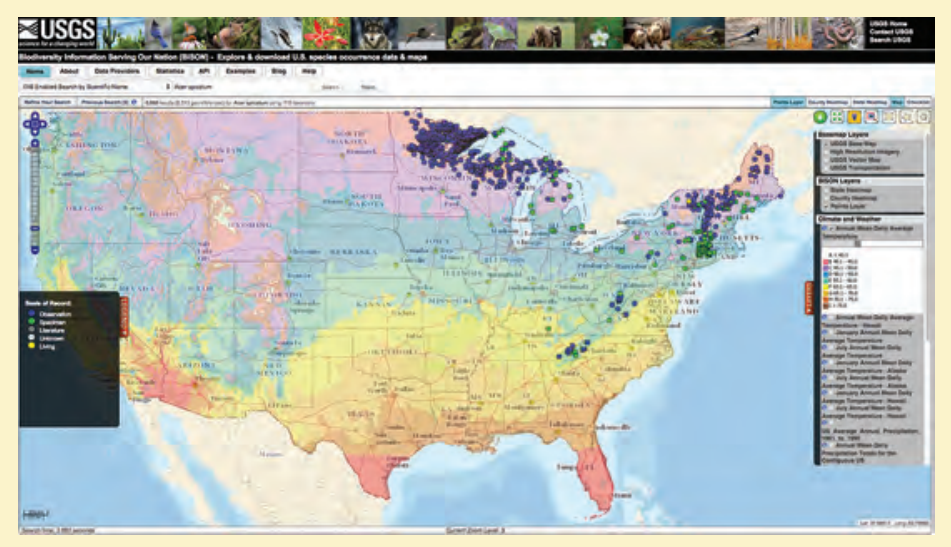

Distribution of a cold-loving tree species, mountain maple (Acer spicatum), shows point occurrences in BISON as they relate to mean annual temperature in the eastern United States (BISON, 2019).
"[BISON] is single handedly making my thesis research possible."

Nathan Sutton, MS candidate, University of Tennessee (2013)

"Systems like BISON help us meet our mission responsibility to information and data."

Donna N. Myers, U.S. Geological Survey, Chief of Office of Water Quality (2015) disseminate to the public USGS

\section{Web Services}

In addition to the website,

BISON has numerous web services (https://bison.usgs.gov/\#api): the Application Programming Interface provides access to the BISON system for web developers; a Web Map Service delivers maps remotely; a REST (REpresentational State Transfer) service generates links to individual species searches in BISON; and a direct interface to the BISON Solr index (a stand-alone enterprise search server) returns query results in JavaScript Object Notation (JSON or JSONP). This allows users to link analytical software and websites directly to BISON and use the power of the large BISON search platform to run their own complex analyses or even to generate unique custom websites powered by BISON.

\section{Taxonomy}

BISON uses standardized scientific names for searching on the web site and a hierarchy and synonymy supplied by the Integrated Taxonomic Information System (ITIS, 2019). For example, users can search for an exact name match to see occurrences only identified as genus Poa, or (with an ITISassisted search) choose to include all taxonomic children and synonyms (and see records for all of the species, subspecies, and varieties of $P o a$, along with all of their synonyms). Names not in ITIS can be searched only as exact matches, but 95 percent of the taxa represented in BISON are found in ITIS. BISON also offers an ITIS Enabled Common Name Search option.

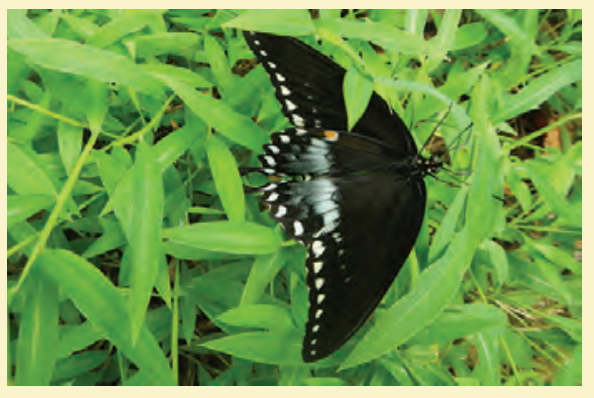

The black swallowtail (Papilio polyxenes) is a butterfly found throughout much of North America where it overwinters as a chrysalis (USGS, 2019). 


\section{National and International Partnerships}

By agreement with the National Science Foundation (NSF), BISON serves as the Federal counterpart to iDigBio (iDigBio, 2019), which is part of the NSF-funded Advancing Digitization of Biodiversity Collections (ADBC) program (Hanken, 2013). BISON has also partnered with members of the North American Invasive Species Management Association in the development of the updated NAISMA invasive species mapping standards (NAISMA, 2018).

The Global Biodiversity Information Facility (GBIF, https://www.gbif.org) is an organization dedicated to facilitating free and open access to biodiversity data worldwide. The U.S. Geological Survey (USGS) administers the U.S. Node of GBIF, and is responsible for encouraging and facilitating U.S. data contributions to GBIF. BISON, by making species occurrence data more broadly accessible and available (in general and to GBIF), helps the USGS fulfill this role.

\section{Geographic and Temporal Scope}

Geographic.-BISON provides access to species occurrence data recorded or collected at locations within the coastal boundaries of the United States and its Territories, U.S. Marine Exclusive Economic Zones, and Canada. Some of these data, however, are contributed by data providers who are not themselves located in the United States or its Territories, or Canada.

It is important to note that the absence of data for any species in BISON does not prove or indicate the absence of that species from North America. Data available through BISON should not be considered comprehensive in terms of species' taxonomic or geographic ranges or distributions.

Temporal.-BISON provides access to species occurrence data from any time period that can be represented with a four digit year (YYYY), which is BISON's minimum requirement for a species occurrence date on which a species' presence was observed, recorded, or collected. BISON does not currently (2019) accommodate geologic time units, but BISON does provide access to species occurrence data that are based on fossil evidence (with date of collection or observation).

\section{Data Fields}

BISON requires only a minimum of four basic species occurrence data fields that are common to most species research datasets: (1) scientific name; (2) occurrence date (ISO-8601 standard format YYYY-MM-DD preferred); (3) latitude and longitude coordinates (point or centroid, preferably decimal degrees), or State name (or FIPS 5-2 standard) and county name (or FIPS 6-4 standard), or other geographic location name reference (national park name, wildlife refuge name, and so on); and (4) collector. But BISON also currently (2019) accommodates and serves

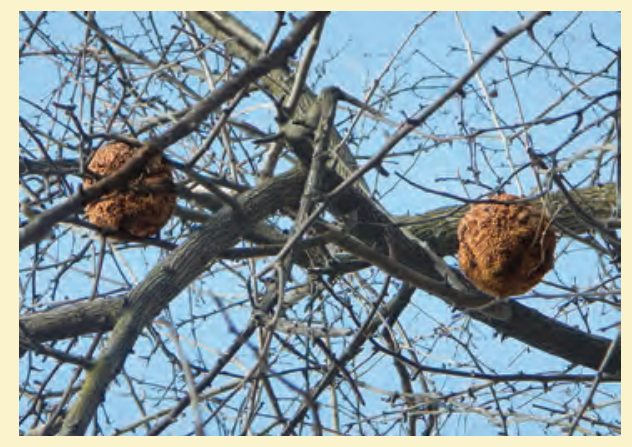

Osage orange (Maclura pomifera) is a small tree native to the southeast and popularly used as fence rows throughout much of the United States. The tree is in the mulberry family, not related to oranges (USGS, 2019).
48 provided or verbatim (original, uncorrected) and calculated (standardized, cleaned) data fields. The internationally developed Darwin Core Standard (Wieczorek and others, 2012) provides the basis for the fields displayed in BISON.

BISON adds value to original, raw datasets by retaining original data field contents, and adding standardized, cleaned data fields. For example, the establishment_means field indicates taxa that are non-native in the conterminous United States, Alaska, and (or) Hawaii. Important information about a species' native status is not always included in original occurrence records. This value-added field informs species' early detection and rapid response actions. This homogeneous collection of fields is available in all BISON records, greatly facilitating indexing and analysis.

\section{Becoming a Data Provider}

If you wish to become a BISON data provider and make your data more broadly available through BISON (and optionally GBIF), please email bison@usgs.gov. As a product developed and supported by the Science Analytics and Synthesis Program of the USGS, the BISON project prioritizes acquisition and processing of datasets from USGS Science Centers, other agencies of the Department of the Interior, and other U.S. Federal and State agencies; followed by institutions, organizations, and individual researchers. BISON also seeks datasets with occurrence records specifically for invasive species or pollinators.

\section{References Cited}

BISON, 2019, Biodiversity Information Serving Our Nation: accessed April 29, 2019, at https://bison.usgs.gov.

Hanken, J., 2013, Biodiversity Online-Toward a network integrated biocollections alliance: Bioscience, v. 63, no. 10, p. 789-790, accessed April 29, 2019, at https://doi.org/10.1525/bio.2013.63.10.4.

iDigBio, 2019, Integrated Digitized Biocollections: accessed April 29, 2019, at https://www.idigbio.org.

ITIS, 2019, Integrated Taxonomic Information System: accessed April 29, 2019, at https://www.itis.gov.

North American Invasive Species Management Association [NAISMA], 2018, Mapping standards for program managers: North American Invasive Species Management Association, 34 p., accessed May 9, 2019, at https://www.naisma.org/images/mappingstandardsfinal.pdf.

U.S. Geological Survey [USGS], 2019, USGS BISON Team-Species recognizable in images and video, biodiversity information serving our Nation: accessed April 29, 2019, at https://bison.usgs.gov/?providerID= $440 \&$ resourceID=100026.

Western Governors' Association, 2018, Invasive species data findings and recommendations: Western Governors' Association, accessed April 29, 2019, at https://westgov.org/images/editor/WGA_Invasive_Species_Data_Findings And_Recommendations.pdf.

Wieczorek, J., Bloom, D., Guralnick, R., Blum, S., Döring M., Giovanni, R., Robertson, T., and Vieglais, D., 2012, Darwin core-An evolving community-developed biodiversity data standard: PLoS ONE, v. 7, no. 10, accessed April 29, 2019, at https://doi.org/10.1371/journal.pone.0029715.

\section{For more information, please contact:}

bison@usgs.gov

Gerald Guala, Branch Chief,

EcoScience Synthesis

Director of BISON and ITIS

Core Science Systems

Mission Area
U.S. Geological Survey

12201 Sunrise Valley Drive, Mailstop 302

Reston, Virginia 20192 USA

Phone: 703-648-4311 